\title{
Evaluation of Post-operative Meningitis: Comparison of Meningitis Caused by Acinetobacter spp. and Other Possible Causes
}

\author{
Gonul CICEK SENTURK¹, Rafet OZAY², Gulnur KUL ${ }^{1}$, Fatma AYBALA ALTAY ${ }^{1}$, Semanur KUZI ${ }^{3}$, Yunus GURBUZ1', \\ Ediz TUTUNCU ${ }^{1}$, Taha ESER ${ }^{4}$
}

'Diskapi Yildirim Beyazit Training and Research Hospital, Department of Infectious Diseases and Clinical Microbiology, Ankara, Turkey ${ }^{2}$ Diskapi Yildirim Beyazit Training and Research Hospital, Department of Neurosurgery, Ankara, Turkey

${ }^{3}$ Artvin State Hospital, Infectious Diseases Clinic, Artvin, Turkey

${ }^{4}$ Dr. Yasar Eryilmaz Dogubayazit State Hospital, Neurosurgery Clinic, Agri, Turkey

This study has been presented as a poster (PP 0194) at the European Congress of Clinical Microbiology and Infectious Diseases (ECCMID) between 21 and 24 April 2018 at Madrid, Spain.

Corresponding author: Gonul CICEK SENTURK drgonulcicek@hotmail.com

\section{ABSTRACT}

AIM: To analyse postoperative meningitis (POM) after craniotomy, and to compare the clinical characteristics, treatment outcomes and mortality rates of POM that were caused by Acinetobacter spp. or other possible causes.

MATERIAL and METHODS: In this study, POM cases in our hospital between 2008 and 2016 were retrospectively reviewed. Cases were divided into three groups; Acinetobacter spp. meningitis (case group), non-Acinetobacter bacterial meningitis (control group 1) and culture negative meningitis (control group 2). Demographic, clinical, laboratory features, treatment modalities and mortality rates were compared between case and control groups.

RESULTS: A total of 112 patients with POM were included in the study. Cerebrospinal fluid (CSF) culture results were negative in $50(44.6 \%)$ patients; bacteria were isolated from CSF of $62(55.3 \%)$ patients. Acinetobacter spp. was isolated from 28 (45\%) patients, while bacteria other than Acinetobacter spp. were detected in 34 (55\%) patients. No significant differences were observed between case and control groups in terms of age, gender, comorbidity and operation type. For the case group, change of treatment according to culture result was significantly different from control groups $(p<0.001)$.

Mortality was $55.6 \%$ in the case group, $24.2 \%$ in control group 1 ( $p=0.013$ ), and $24 \%$ in control group 2 ( $p=0.006)$. In multivariate analysis, isolation of $A$ cinetobacter spp. from CSF culture $\left[\mathrm{OR}_{\mathrm{adj}} 5.2,95 \%\right.$ confidence interval $\left.(\mathrm{Cl}): 1.2-22.0, \mathrm{p}=0.026\right]$ and inappropriate treatment $\left(\mathrm{OR}_{\mathrm{adj}} 15.7,95 \% \mathrm{Cl}: 3.6-68.9, \mathrm{p}<0.001\right)$ were determined to be independent risk factors for mortality.

CONCLUSION: Postoperative meningitis, especially caused by Acinetobacter spp., and its inappropriate empirical treatment are associated with high mortality.

KEYWORDS: Acinetobacter spp., Antimicrobial resistance, Empiric antibiotic treatment, Mortality, Postoperative meningitis

Gonul CICEK SENTURK (D) : 0000-0001-7959-3125 Rafet OZAY

Gulnur KUL
Fatma AYBALA ALTAY (D) : 0000-0002-7149-2968 Semanur KUZI D : 0000-0001-6496-1773 Yunus GURBUZ (D) : 0000-0002-8772-0769
Ediz TUTUNCU (D) : 0000-0002-7583-8081 Taha ESER (D) : 0000-0002-1391-4341 


\section{INTRODUCTION}

$\mathrm{P}$ ostoperative meningitis (POM) is a serious condition, which develops in rare cases in patients who have undergone neurosurgical procedures and requires appropriate urgent intervention (16,21). POM incidence varies between $0.3 \%-7 \%$, while infection rates can reach as high as $10 \%$ in the absence of antibiotic prophylaxis $(2,26)$. The most common pathogenic agents in POM are staphylococci; however, the reported involvement of Gram (-) agents has increased recently (2). Among Gram (-) bacteria, Acinetobacteria are the most common cause of POM. Within the past three decades, infections caused by Acinetobacter have become ubiquitous (2). Acinetobacter spp. are among the leading causes of nosocomial infections, especially in intensive care units, and have become a significant health problem. Natural resistance to many drugs, and the ability to easily gain new resistance mechanisms, makes the treatment of Acinetobacter infections more difficult $(7,8)$. The purpose of this unique research is to analyse postoperative meningitis rate after craniotomy, and to compare the clinical characteristics, treatment outcomes and mortality rates of postoperative meningitis that were caused by Acinetobacter spp. or other possible causes.

\section{MATERIAL and METHODS}

In this study, cases of postoperative meningitis, developed in our hospital between 2008 and 2016, were evaluated retrospectively. Cases with Acinetobacter spp. growth in the cerebrospinal fluid (CSF) were included in the case group, those with bacterial growth other than Acinetobacter spp. were included in Control Group 1 and those with no microbial growth in the CSF were included in Control Group 2. Postoperative meningitis was described according to guidelines by the Centers for Disease Control and Prevention (CDC) (7). Patients younger than 18 years of age were excluded.

Bacterial strains were named, and species determination were performed using VITEK 2 automated microbial identification system (BioMérieux), API 20 E (Biomérieux), API 20 Strep semi-automated system and conventional methods. Antibiotic susceptibility was determined based on Clinical and Laboratory Standard Institute criteria and European Committee on Antimicrobial Susceptibility Testing criteria, using VITEK 2 antibiotic susceptibility testing (BioMérieux), disc diffusion (Becton Dickinson) and gradient diffusion test (Becton Dickinson) methods. Empirical therapy is defined as antibiotic treatment performed in order to treat a suspicious infection prior to the definition of the pathogenic agent and its susceptibility. Proper antibiotics is defined as positive susceptibility of the identified microorganism to empirical treatment commenced invitro.

Patients who underwent craniotomy in our hospital were followed-up for three months postoperatively by the Hospital Infection Control Committee (HICC) towards active infection surveillance.

\section{Statistical Analysis}

Statistical analyses included separate comparisons between the case group and both control group 1 and 2 .
Descriptive statistics and advanced analyses were performed using SPSS Statistics V23.0 and Open Epi program packages.

Data analysis included the calculation of numeric and percentage distributions, 95\% confidence interval $(\mathrm{Cl})$ for evaluation of potential risk factors, $5 \%$ standard error and estimated odds ratio (OR). Chi-square and Fisher's exact chi-square tests were used to evaluate categorical variables; student t-test for independent samples was used to evaluate the difference between means.

Factors related to mortality in patients with postoperative meningitis were evaluated using multivariate analyses. A logistic regression model was formed for multivariate analysis of mortality risk factors for the case group and control groups. Logistic regression analyses included $95 \% \mathrm{Cl}$, adjusted odds ratio $\left(\mathrm{OR}_{\mathrm{adj}}\right)$ and Wald test.

When determining variables for inclusion in the model, those with $p<0.05$ from univariate analyses and those believed to be clinically important were included, and the decision was based on a subsequent backward stepwise method. Furthermore, variables were inspected with regards to changes in efficacy, and no changes were reported.

During this examination, two separate models were formed: the first model included the case group, control group 2 and treatment propriety; the second model included the case group, control group 1 and treatment propriety variables.

A p value $<0.05$ was considered statistically significant.

\section{- RESULTS}

A total of 719 craniotomies were performed in our hospital between January 2015 and December 2016. According to the data reporting active surveillance performed by HICC, the postoperative meningitis rate was $3.3 \%$.

One hundred and twelve patients with postoperative meningitis were included in the study. Bacteria were isolated from CSF of $62(55.3 \%)$ patients. Among the patients from whom bacteria were isolated, 28 (45\%) revealed Acinetobacter spp. growth in CSF and 34 (55\%) revealed microbial growth other than Acinetobacter spp. CSF culture results were negative in 50 of the $112(44.6 \%)$ patients. Microorganism growth in CSF is summarised in Table I.

No differences were observed between case and control groups regarding age, gender, comorbidity or the type of operation performed. Mean durations of preoperative hospital stay, including standard deviation (SD), were $1.9 \pm 2.5$ days, $4.5 \pm 4.8$ days $(p=0.01)$ and $5.0 \pm 4.8$ days $(p<0.001)$ for the study group, control group 1 and control group 2, respectively, revealing statistically significant differences between the case group and control groups. Postoperative symptoms and findings revealed no significant differences between groups regarding postoperative consciousness, duration until onset of first symptom or symptoms developed (headache, blurred consciousness or fever). No significant differences were observed between groups, following the diagnosis of postoperative meningitis, regarding Glasgow Coma Scale, 
either $(p=0.086$ and $p=0.128$ between the case group and control group 1 and 2 , respectively).

In the case group at the time of postoperative meningitis diagnosis, an extraventricular drainage catheter (EVD) was present in 14 of $28(50 \%)$ patients, and a lumbar drainage catheter (LD) was present in three patients (10\%). In control group 1, 16 of 34 patients (47\%) had an EVD and 5 (15\%) had an LD ( $\mathrm{p}=0.8$, OR 1.2, 95\% Cl:0.4-3.1; $\mathrm{p}=0.7$ OR 0.7, 95\% $\mathrm{Cl}: 0.2-3.2$, respectively). In control group 2, 12 of 50 patients (24\%) had an EVD and 5 (10\%) had an LD ( $p=0.019$, OR 3,2, 95\% Cl: 1.2-8.5; $p=1$, OR 1.1, 95\% Cl: 0.2-4.9, respectively). Mean duration until development of meningitis following placement of an EVD/LD (including SD) was $6.5 \pm 6.1$ for the case group, $4.3 \pm 2.5(p=0.4)$ for control group 1 and $1.2 \pm 1.2$ $(p=0.018)$ for control group 2 . In the case group, $6(37.5 \%)$ EVD/LD catheters were placed at bedside and 10 (62\%) were placed in the operating room; in control group 1, 3 (16\%) $(p=0.25)$ were placed at bedside, and in control group 2, 5 $(27 \%)(p=0.54)$ were placed at bedside.

Mean leukocyte count at the time of meningitis diagnosis (including SD) was $17850 \pm 7301$ per $\mu \mathrm{L}$ for the case group, $13312 \pm 5240$ per $\mu \mathrm{L}(\mathrm{p}=0.006)$ for control group 1 and 14620 \pm 5847 per $\mu \mathrm{L}(p=0.037)$ for control group 2. Mean blood CRP (C-reactive protein) level (including SD) was $201 \pm 137 \mathrm{mg} /$ $\mathrm{L}$ (normal range:0-8 mg/L) for the case group, $108 \pm 116 \mathrm{mg} / \mathrm{L}$ $(p=0.016)$ for control group 1 and $137 \pm 71 \mathrm{mg} / \mathrm{L}(\mathrm{p}=0.003)$ for control group 2. Mean leukocyte cell count in CSF (including $\mathrm{SD})$ was $4635 \pm 11078$ per $\mu \mathrm{L}$ for the case group, $645 \pm 716$ per $\mu \mathrm{L}(\mathrm{p}=0.068)$ for control group 1 and $579 \pm 953$ per $\mu \mathrm{L}$ $(p=0.064)$ for control group 2. Mean glucose level in CSF (including SD) was $41 \pm 37 \mathrm{mg} / \mathrm{mL}$ for the case group, 51 $\pm 39 \mathrm{mg} / \mathrm{mL}(\mathrm{p}=0.331)$ for control group 1 and $57 \pm 30 \mathrm{mg} /$ $\mathrm{mL}(\mathrm{p}=0.055)$ for control group 2. Mean protein level in CSF (including SD) was $404 \pm 448 \mathrm{mg} / \mathrm{mL}$ for the case group, 228 $\pm 290 \mathrm{mg} / \mathrm{mL}(\mathrm{p}=0.1)$ for control group 1 and $344 \pm 864 \mathrm{mg} /$ $\mathrm{mL}(\mathrm{p}=0.749)$ for control group 2 .

Of the 28 patients in the case group, 26 (93\%) possessed Acinetobacter spp. in CSF, which were resistant to both imipenem and meropenem.

Empirical treatment was commenced in $89 \%$ of patients in the case group, $83 \%$ of patients in control group 1 and $100 \%$ of patients in control group 2 . In the case group, $78 \%$ of patients were started on meropenem + vancomycine and $12 \%$ on meropenem + vancomycine + colistin; in control group 1 and $2,90 \%$ and $98 \%$ of patients were started on meropenem + vancomycine, respectively. Empirical treatment with meropenem+vancomycine+colistin was commenced in 3\% and $2 \%$ of the patients in control group 1 and 2 , respectively. Therapies for $82 \%$ of patients in the case group and $21 \%$ of patients in control group 1 ( $p<0.001$, OR 16.3, 95\% Cl: 4.558.8) were modified based on the results of microbial culture.

Univariate analyses of mortality-related factors for all patients included in the study are presented in Table II.

Multivariate analyses of mortality data between case group and both control groups are presented in Table III.
Table I: Microorganism Growth in Postoperative Meningitis in CSF

\begin{tabular}{lc}
\hline Microorganism & $\mathbf{n = 6 2 ( \% )}$ \\
\hline Acinetobacter spp. & $28(45)$ \\
MRCoNS $^{*}$ & $11(18)$ \\
E.coli & $3(5)$ \\
K.pneumonia & $3(5)$ \\
Pseudomonas spp. & $3(5)$ \\
Enterococcus spp. & $3(5)$ \\
S.pneumonia & $2(3)$ \\
Serratia spp. $_{\text {Others }^{\dagger}}$ & $2(3)$ \\
\hline
\end{tabular}

*: MRCoNS: Methicillin resistant coagulase negative Staphylococcus, t: Haemophilus influenzae, Streptococcus oralis, Corynebacterium striatum, Burkholderia cepacia, Methicillin Sensitive Staphylococcus aureus.

\section{DISCUSSION}

Diagnosis of postoperative meningitis is made based on clinical findings and examination of CSF. However, CSF cell count, glucose and/or protein level abnormalities may not be reliable parameters for indication of infection in patients with nosocomial meningitis (20). Normal CSF cell count and glucose and protein levels are not sufficient to reliably exclude infection in patients with nosocomial meningitis; however, CSF and blood samples should be collected prior to antibiotic treatment in selected patients. Negative CSF growth cannot exclude nosocomial meningitis in patients who have undergone previous antibiotic treatment. Bacterial growth was observed in CSF of 62 (55\%) patients included in our study, while no growth was observed in 50 (45\%); the patients with no growth were accepted as aseptic meningitis. Aseptic meningitis comprises $60 \%-75 \%$ of all postoperative meningitis cases. Findings in aseptic and bacterial meningitis are often similar; discrimination is made upon the outcome of CSF culture (27). According to a study by Chidambaram et al., bacterial growth was observed in the CSF in only $9.8 \%$ of POM cases, with the remaining $91 \%$ being accepted as aseptic meningitis (4). Zarrouk et al. reported that 54 of 75 cases with POM (75\%) were accepted as aseptic meningitis owing to a lack of bacterial growth (27). Meningitis is a disease with high rates of mortality and morbidity, which can be fully ameliorated with appropriate treatment. Considering both clinical findings and CSF results, we believe that diagnosis should be made in favour of meningitis in cases in whichboth postoperative changes and meningitis are suspected. However, this may lead to the incidence of aseptic meningitis being over-reported.

In the present study, 28 of the 62 cases in which the growth of microorganisms was detected in CSF (45\%) were confirmed to have Acinetobacter spp. Acinetobacter is frequently observed among nosocomial infections, including in a growing number of POM cases recently. In previous studies, both Gram (-) (3), and Gram (+) (particularly Staphylococcus aureus) $(10,26)$, bacteria have been shown to predominate, varying between countries $(14,22,23)$. However, the incidence of Gram (-) agents has increased over the past three decades. Recent 
Table II: Mortality Related Factors in Patients with Postoperative Meningitis (Univariate Analysis)

\begin{tabular}{|c|c|c|c|c|c|c|}
\hline \multirow[t]{2}{*}{ Factors } & \multicolumn{2}{|c|}{ Non-survivors $\mathrm{n}=35$} & \multicolumn{2}{|c|}{ Survivors $\mathrm{n}=75$} & \multirow[t]{2}{*}{$\mathbf{p}$} & \multirow[t]{2}{*}{ OR (\%95 Cl) } \\
\hline & $\mathbf{n}$ & $\%$ & $\mathbf{n}$ & $\%$ & & \\
\hline Age (mean $\pm \mathrm{SD})$ & \multicolumn{2}{|c|}{$47.6 \pm 14.4$} & \multicolumn{2}{|c|}{$43.2 \pm 15.9$} & 0.170 & - \\
\hline \multicolumn{7}{|l|}{ Gender } \\
\hline Male & 16 & 45.7 & 39 & 52.0 & 0.539 & $0.8(0.4-1.7)$ \\
\hline Female & 19 & 54.3 & 36 & 48.0 & & \\
\hline Glasgow Coma Score & \multicolumn{2}{|c|}{$9.3 \pm 4.6$} & \multicolumn{2}{|c|}{$12.3 \pm 3.9$} & 0.005 & - \\
\hline \multicolumn{7}{|l|}{ EVD } \\
\hline Done & 14 & 40.0 & 26 & 34.7 & 0.588 & $1.3(0.6-2.9)$ \\
\hline Not done & 21 & 60.0 & 49 & 65.3 & & \\
\hline \multicolumn{7}{|l|}{ LD } \\
\hline Done & 5 & 14.3 & 8 & 10.7 & $0.398^{*}$ & $1.4(0.4-4.6)$ \\
\hline Not done & 30 & 85.7 & 67 & 89.3 & & \\
\hline \multicolumn{7}{|l|}{ Empirical treatment } \\
\hline Recieved & 32 & 91.4 & 68 & 91.9 & $0.599^{*}$ & $0.9(0.2-4.0)$ \\
\hline Not recieved & 3 & 8.6 & 6 & 8.1 & & \\
\hline \multicolumn{7}{|l|}{ Antibioticused in empirical treatment } \\
\hline Meropenem+Vancomycine & 27 & 84.4 & 68 & 93.3 & $0.147^{*}$ & $0.4(0.1-1.5)$ \\
\hline Meropenem+Vancomycine & 3 & 8.8 & 2 & 2.8 & $0.187^{*}$ & $3.4(0.5-21.3)$ \\
\hline Treatment change according to microbial culture & 15 & 42.9 & 14 & 18.9 & 0.008 & $3.2(1.3-7.8)$ \\
\hline \multicolumn{7}{|l|}{ Propriety of the treatment } \\
\hline Unproper & 20 & 58.8 & 17 & 24.3 & 0.001 & $4.5(1.9-10.7)$ \\
\hline Proper & 14 & 41.2 & 53 & 75.7 & & \\
\hline Leukocytecount & \multicolumn{2}{|c|}{$16441 \pm 7140$} & \multicolumn{2}{|c|}{$14399 \pm 5857$} & 0.119 & - \\
\hline $\mathrm{CRP}(\mathrm{mg} / \mathrm{L})$ & \multicolumn{2}{|c|}{$197.6 \pm 136.2$} & \multicolumn{2}{|c|}{$99.4 \pm 88.3$} & $<0.001$ & - \\
\hline Duration of hospital stay until the operation (days) & \multicolumn{2}{|c|}{$3.1 \pm 4.5$} & \multicolumn{2}{|c|}{$4.5 \pm 4.4$} & 0.145 & - \\
\hline Duration until postop symptoms (days) & \multicolumn{2}{|c|}{$10.5 \pm 7.8$} & \multicolumn{2}{|c|}{$8.8 \pm 11.1$} & 0.472 & - \\
\hline \multicolumn{5}{|l|}{ Bacterial growth in CSF } & & - \\
\hline Acinetobacter spp. & 15 & 42.9 & 12 & 16.0 & 0.002 & $3.9(1.6-9.8)$ \\
\hline Other bacteria & 20 & 57.1 & 63 & 84.0 & & \\
\hline
\end{tabular}

*: Fisher's exact test.

studies have reported Acinetobacter as the causative agent in as many as $30 \%$ of meningitis cases $(15,19)$. Findings from the present study are in accordance with data from such studies.

It is well known that many sites of the human body contain flora, which act as barriers to infection. However, within several days of hospitalisation (generally after the fourth day), floral bacteria start to be replaced by resistant bacteria of endogeneous or exogeneous origin. Therefore, we sought to investigate the relationship between duration of preoperative hospitalisation and causative agents of meningitis. Longterm preoperative hospitalisation was expected to be a risk factor for Acinetobacter growth. On the contrary, duration of preoperative hospitalisation was significantly lower in the case group compared with either control group. No existing data comparisons on this topic were found in previous literature. Demirarslan et al. previously investigated antibiotic treatment, reporting significantly higher rates of antibiotic usage and 
Table III: Mortality Related Factors in Case and Control Groups and all Patients (Multivariate Analysis)

\begin{tabular}{|c|c|c|c|c|}
\hline Risk factors & $\begin{array}{c}\text { Non-survivors } \\
(\%)\end{array}$ & $\begin{array}{c}\text { Survivors } \\
(\%)\end{array}$ & OR $_{\text {adj }}^{*}\left(\% 95 \mathrm{Cl}^{\dagger}\right)$ & $\mathbf{p}$ \\
\hline \multicolumn{5}{|c|}{ Mortality related risk factors in the case group and control group 1} \\
\hline Unproper treatment & 58.8 & 24.3 & $15.7(3.6-68.9)$ & $<0.001$ \\
\hline \multicolumn{5}{|c|}{ Mortality related risk factors in all patients } \\
\hline Acinetobacter spp. growth & 65.2 & 32.4 & $2.7(0.8-9.2)$ & 0.104 \\
\hline Unproper treatment & 58.8 & 24.3 & $6.8(2.0-23.3)$ & 0.002 \\
\hline
\end{tabular}

*: Adjusted odds ratio; †: Confidence interval; ¥: C-reactive protein.

duration of antibiotic treatment in the group with Acinetobacter growth and previous antibiotic treatment (5).

No differences were observed regarding symptoms or clinical findings (headache, blurred consciousness or fever) upon diagnosis of POM between case and control groups. Similar findings were reported by Kurtaran et al. when comparing POM with Gram (-) and Gram (+) bacterial growth (15).

The relationship between EVD/LD and bacterial agents in meningitis is well known. Dos Santos et al. previously defined the presence of EVD/LD as a risk factor for the development of POM in both uni and multivariate analyses (6). However, in this study, no comparisons were made between types of bacteria. Kurtaran et al. observed no difference between Gram (-) and Gram (+) bacteria incidences in the presence of an EVD/LD. In the present study, presence of an EVD/LD was not detected as a risk factor for development of Acineto bacter meningitis (15).

In the present study, mean duration until development of meningitis following placement of an EVD/LD was significantly higher for the case group than that in the control group $2(p=0.018)$. In a multi-centre study by Jamjoom et al., coagulase negative staphylococci and S.aureus growth were predominant in the CSF of patients with an EVD (13). Furthermore, it has been reported that EVDs used for longer than 10 days significantly increase the rate of infection; this is independent of the type of bacteria (6).

Proper hand and hair hygiene, provision of full body drapes, full use of protective equipment and antiseptic preparation during EVD placement would reduce the risk of infection. Previous studies have reported that EVDs should be placed in the operating room rather than the emergency unit so these conditions can be better met; equally, in case of the need for EVD placement at home, it has been recommended for each institute to create a protocol for placement (18). In our study, no differences were detected regarding Acinetobacter growth following EVD/LD placement in the operation room or bedside between the case and control groups. In a metaanalysis investigating the effect of such protocols on infection rates, consistent and significant benefits were reported in all studies, despite the poor quality of literature supporting EVD placement protocols.

In the present study, leukocyte count and CRP levels (as indicators of systemic inflammatory response in the blood) were compared between the case and control groups at the time of POM diagnosis. Blood leukocyte count and CRP levels were significantly higher in the case group than those in either control groups. No differences were detected in the leukocyte count, glucose or protein levels in CSF between case and control groups. Kurtaran et al. previously reported, when comparing Gram (-) and Gram (+) agents, that blood and CSF leukocyte count and blood CRP levels were similar between both groups, whereas CSF glucose, protein and lactate levels were significantly higher in the Gram (-) group (15).

The Central Asian and Eastern European Surveillance of Antimicrobial Resistance (CAESAR) 2017 annual report by the World Health Organization indicated that, in Turkey, carbapenem resistance among Acinetobacter spp. in blood and CSF was $92 \%$. The same report also indicated that carbapenem resistance among Acinetobacter spp. isolates grown in blood and CSF in all countries surveyed varied between $70 \%$ and $97 \%$, with the exception of Switzerland (7\%) (25). According to the European Antimicrobial Resistance Surveillance Networkdata, combined resistance of fluoroquinolones, aminoglycosides and carbapenems in Acinetobacteria varies between countries, ranging widely between $>1 \%$ and $<75 \%$ (24). In the present study, carbapenem resistance in Acinetobacter spp. was $93 \%(26 / 28)$, in keeping with the findings of CAESAR.

POM is an infectious disease, which necessitates urgent appropriate treatment. Appropriate empirical treatment should be commenced immediately on suspicion of meningitis. The combined usage of vancomycine and anti-pseudomonal $\beta$-lactam (cefepim, ceftazidime or meropenem) antibiotics is 
recommended for empirical treatment of POM in the 'Healthcare-Associated Ventriculitis and Meningitis'practice guidelines published by the Infectious Diseases Society of Americain 2017 (20). Among 95 (85\%) patients included in our study treated with meropenem+vancomycin, 5 (4\%) were started on empirical treatment with meropenem+vancomycin+colistin. Treatments for $82 \%$ of patients in the case group and $21 \%$ of patients in control group $1(p<0.001$, OR 16,$3 ; 95 \% \mathrm{Cl}$ : 4.5-58.8) were modified according to results of bacterial culture and antibiotic susceptibility tests. This indicates that the causative agent was Acinetobacter spp., and that empirical antibiotic treatment was insufficient for POM. This is not unexpected, considering CAESAR data discussed above regarding resistance rates of these bacteria. Accounting for specific data from each institute, colistin therefore seems to be an important option for empirical treatment of POM.

Previous studies have reported POM mortality rates of between $15 \%$ and $71.4 \%(3,9,11,17)$. Metan et al., investigating Acinetobacter meningitis, reported a mortality rate of $71.4 \%$ (17). According to the literature, POM mortality rates are higher when caused by Gram (-) bacteria than Gram (+) bacteria $(1,9,15)$. Such high mortality rates may be explained by high global rates of antimicrobial resistance in Gram (-) bacilli (17). In instances of antibiotic resistance, treatment regimes are inappropriate, therefore poor mortality and morbidity outcomes are observed. However, in addition to improper empirical treatment, underlying neurological situations or additional comorbidities can also result in poor mortality and morbidity outcomes. In the present study, mortality was $55.6 \%$ for the case group, $24.2 \%$ for control group 1 ( $p=0.013)$, and $24 \%$ for control group $2(p=0.006)$. In multivariate analysis, presence of Acinetobacter spp.in CSF culture $\left(\mathrm{OR}_{\mathrm{adj}} 5.2,95 \% \mathrm{Cl}: 1.2-22.0, \mathrm{p}=0.026\right)$ and inappropriate treatment $\left(\mathrm{OR}_{\mathrm{adj}} 15.7,95 \% \mathrm{Cl}: 3.6-68.9, \mathrm{p}<0.001\right)$ were both determined to be independent risk factors for mortality. These results strongly support data reported in the literature.

The most important limitations of this study were its retrospective nature and long duration. Therefore, we did not approve of reporting POM rates between 2008 and 2016. Instead, it was more appropriate to give HICC results of active surveillance from the past two years (2015-2016) in our hospital.

\section{CONCLUSION}

POM leads to high mortality and morbidity rates if not appropriately and urgently treated. Data from the present study support this hypothesis. Every institute should consider its own antimicrobial resistance rate when making a decision regarding empirical treatment. Finally, colistin seems to be an important option, which may be used for empirical treatment.

\section{ACKNOWLEDGEMENT}

We thank to epidemiologist Dr. Fehminaz Temel for her help in statistical analysis.

\section{- REFERENCES}

1. Bardak-Ozcem S, Sipahi OR: An updated approach to healthcare-associated meningitis. Expert Rev Anti Infect Ther 12(3):333-342,2014

2. Cascio A, Conti A, Sinardi L, laria C, Angileri FF, Stassi G, David T, Versaci A, laria M, David A: Post-neurosurgical multidrugresistant Acinetobacter baumannii meningitis successfully treated with intrathecal colistin. A new case and a systematic review of the literature. Int J Infect Dis 14(7):e572-579, 2010

3. Chang CJ, Ye JJ, Yang CC, Huang PY, Chiang PC, Lee MH: Influence of third-generation cephalosporin resistance on adult in-hospital mortality from post-neurosurgical bacterial meningitis. J Microbiol Immunol Infect 43(4):301-309,2010

4. Chidambaram S, Nair MN, Krishnan SS, Cai L, Gu W, Vasudevan MC: Postoperative central nervous system infection after neurosurgery in a modernized, resource-limited tertiary neurosurgical center in South Asia. World Neurosurg 84(6):1668-1673, 2015

5. Demiraslan H, Ulutabanca H, Ercal B, Metan G, Alp E: Does antimicrobial usage before meningitis lead to a higher risk of adult postsurgical Acinetobacter baumannii meningitis than that of Enterobacteriaceae meningitis? Infez Med 24(4):293298, 2016

6. Dos Santos SC, Fortes Lima TT, Lunardi LW, Stefani MA: External ventricular drain-related infection in spontaneous intracerebral hemorrhage. World Neurosurg 99:580-583, 2017

7. Eliopoulos GM, Maragakis LL, Perl TM: Acinetobacter baumannii: Epidemiology, antimicrobial resistance, and treatment options. Clin Infect Dis 46(8):1254-1263,2008

8. Erac B, Yilmaz FF, Hosgor Limoncu M, Ozturk I, Aydemir S: Investigation of the virulence factors of multidrug-resistant Acinetobacter baumannii isolates. Mikrobiyol Bul 48(1):70-81, 2014

9. Erdem I, Hakan T, Ceran N, Metin F, Akcay SS, Kucukercan M, Berkman MZ, Goktas P: Clinical features, laboratory data, management and the risk factors that affect the mortality in patients with postoperative meningitis. Neurol India 56(4):433437, 2008

10. Erman T, Demirhindi H, Gocer Al, Tuna M, Ildan F, Boyar B: Risk factors for surgical site infections in neurosurgery patients with antibiotic prophylaxis. Surg Neurol 63(2):107-113, 2005

11. Huang CR, Lu CH, Chuang YC, Tsai NW, Chang CC, Chen SF, Wang HC, Chien CC, Chang WN: Adult Pseudomonas aeruginosa meningitis: High incidence of underlying medical and/or postneurosurgical conditions and high mortality rate. Jpn J Infect Dis 60(6):397-399, 2007

12. Horan TC, Andrus M, Dudeck MA: CDC/NHSN surveillance definition of health care-associated infection and criteria for specific types of infections in the acute care setting. Am J Infect Control 36(5):309-332, 2008

13. Jamjoom AAB, Joannides A, Poon MT, Chari A, Zaben M, Abdulla MAH, Roach J, Glancz LJ, Solth A, Duddy J, Brennan PM, Bayston, Bulters DO, Mallucci CL, Jenkinson MD, Gray WP, Kandasamy J, Hutchinson PJ, Kolias AG, Ahmed Al; British Neurosurgical Trainee Research Collaborative. Prospective, multicentre study of external ventricular drainage-related infections in the UK and Ireland. J Neurol Neurosurg Psychiatry 89(2):120-126, 2018 
14. Kim HI, Kim SW, Park GY, Kwon EG, Kim HH, Jeong JY, Chang $\mathrm{HH}$, Lee JM, Kim NS: The causes and treatment outcomes of 91 patients with adult nosocomial meningitis. Korean J Intern Med 27(2):171-179, 2012

15. Kurtaran B, Kuscu F, Ulu A, Inal AS, Komur S, Kibar F, Cetinalp NE, Ozsoy KM, Arslan YK, Yilmaz DM, Aksu H, Tasova Y: The causes of postoperative meningitis: The comparison of gram-negative and gram-positive pathogens. Turk Neurosurg 28(4):589-596,2018

16. McClelland S 3rd, Hall WA: Postoperative central nervous system infection: Incidence and associated factors in 2111 neurosurgical procedures. Clin Infect Dis 45(1):55-59,2007

17. Metan G, Alp E, Aygen B, Sumerkan B: Acinetobacter baumannii meningitis in post-neurosurgical patients: Clinical outcome and impact of carbapenem resistance. J Antimicrob Chemother 60(1):197-199, 2007

18. Sieg EP, Schlauderaff AC, Payne R, Glantz MJ, Simon SD: Impact of an external ventricular drain placement and handling protocol on infection rates: A meta-analysis and single institution experience. World Neurosurg 115:e53-e58, 2018

19. Sipahi OR, Nazli Zeka A, Tasbakan M, Pullukcu H, Arda B, Yamazhan T, Sipahi H, Ulusoy S: Pooled analysis of 899 nosocomial meningitis episodes from Turkey. Turk J Med Sci 47(1):29-33, 2017

20. Tunkel AR, Hasbun R, Bhimraj A, Byers, Kaplan SL, Michael Scheld, van de Beek, Bleck T, Garton H, Zunt JR: 2017 infectious diseases society of america's clinical practice guidelines for healthcare-associated ventriculitis and meningitis. Clin Infect Dis 2017 (Epub ahead of print)
21. Van de Beek D, Drake JM, Tunkel AR: Nosocomial bacterial meningitis. New N Engl J Med 362(2):146-154, 2010

22. Wang KW, Chang WN, Huang CR, Tsai NW, Tsui HW, Wang HC, Su TM, Rau CS, Cheng BC, Chang CS, Chuang YC, Liliang PC, Tsai YD, Lu CH: Post-neurosurgical nosocomial bacterial meningitis in adults: Microbiology, clinical features, and outcomes. J Clin Neurosci 12(6):647-650, 2005

23. Weisfelt M, van de Beek D, Spanjaard L, de Gans J: Nosocomial bacterial meningitis in adults: A prospective series of 50 cases. J Hosp Infect 66(1):71-78, 2007

24. World Health Organization: Antimicrobial resistance: Global report on surveillance 2014. France: WHO Press, 2014:1-257

25. World Health Organization: Central Asian and Eastern European surveillance of antimicrobial resistance. Annual report 2016. Denmark: Copenhagen, 2016:1-134

26. Yadegarynia D, Gachkar L, Fatemi A, Zali A, Nobari N, Asoodeh M, Parsaieyan Z: Changing pattern of infectious agents in postneurosurgical meningitis. Caspian $\mathrm{J}$ Intern Med 5(3): $170-175,2014$

27. Zarrouk V, Vassor I, Bert F, Bouccara D, Kalamarides M, Bendersky N, Redondo A, Sterkers O, Fantin B: Evaluation of the management of postoperative aseptic meningitis. Clin Infect Dis 44(12):1555-1559, 2007 